\title{
The Austrian Biosphere Reserves. A (connoisseur's) world beyond the cookery book
}

\author{
Günter Köck, Martha Umhack \& Christian Diry
}

Keywords: UNESCO, Man and the Biosphere Programme, biosphere reserves, sustainable development, school initiative

\section{Abstract}

In many instances the Austrian UNESCO Biosphere Reserves as model regions of sustainable development are outshone by other conservation categories, such as national parks or world heritage sites, and are largely unknown to the wider population. This shadowy existence is ill deserved. The modern concept of biosphere reserves (BRs) is more important today than it ever was if we want to maintain valuable cultural landscapes for later generations. The Austrian MAB National Committee therefore made it a priority to greatly increase the popularity of our BRs and to underline their significance for sustainability research. Moreover, efforts in this vein should involve young people. The project Vielfalt Genießen (Enjoying diversity) has been conceived as a three-stage programme, starting with a schools competition during the International Year of Biodiversity 2010, followed by the publication of an award-winning cookery book (The Austrian Biosphere Reserves. A Connoisseur's World) and culminating in a BR training for students, lasting more than a year, carried out at the Landesberufsschule Waldegg (vocational college for the hotel and catering trades) and complemented with BR-related activities (BR recipes, information folder) in selected restaurants around Wienerwald BR.
Profile

Protected area

Wienerwald Biosphere Reserve

Mountain range

Alps

Country

Austria

\section{Background}

In 2011 the research programme Man and the Biosphere (MAB) celebrated its $40^{\text {th }}$ anniversary, which makes it one of the longest-standing UNESCO programmes. A key component of the MAB programme is the global network of UNESCO BRs (currently 621 BRs in 117 countries, with 7 BRs in Austria), where models of sustainable development, combined with environmental protection, are developed, tried and tested, and then implemented in cooperation with the regional population. And yet, UNESCO BRs as model regions and educational sites for sustainable development, unlike other conservation categories, such as national parks or world heritage sites, are often largely unknown to the wider population (Lange 2005; Schrader 2006; Coetzer et al. 2013). Why is this shadowy existence? Several reasons spring to mind: while the first ever national park, Yellowstone National Park in the USA, was founded in 1872, BRs have only been around for just under 40 years. Famous tourist destinations, such as Kruger National Park in South Africa or Galapagos National Park in Ecuador, have contributed to turning the national park label into a world-famous brand. A similar development took place with UNESCO World Heritage Sites (WHS). Here, too, legendary destinations, strong advertising, as well as the significant political role of the WHS label combined to enhance its popularity, which greatly outstrips that of the in-house Biosphere Reserve brand. Added complications emerge when in certain regions, in Austria for instance in the Lake Neusiedl region, all three categories overlap. Advertising efforts usually focus on the best-known label

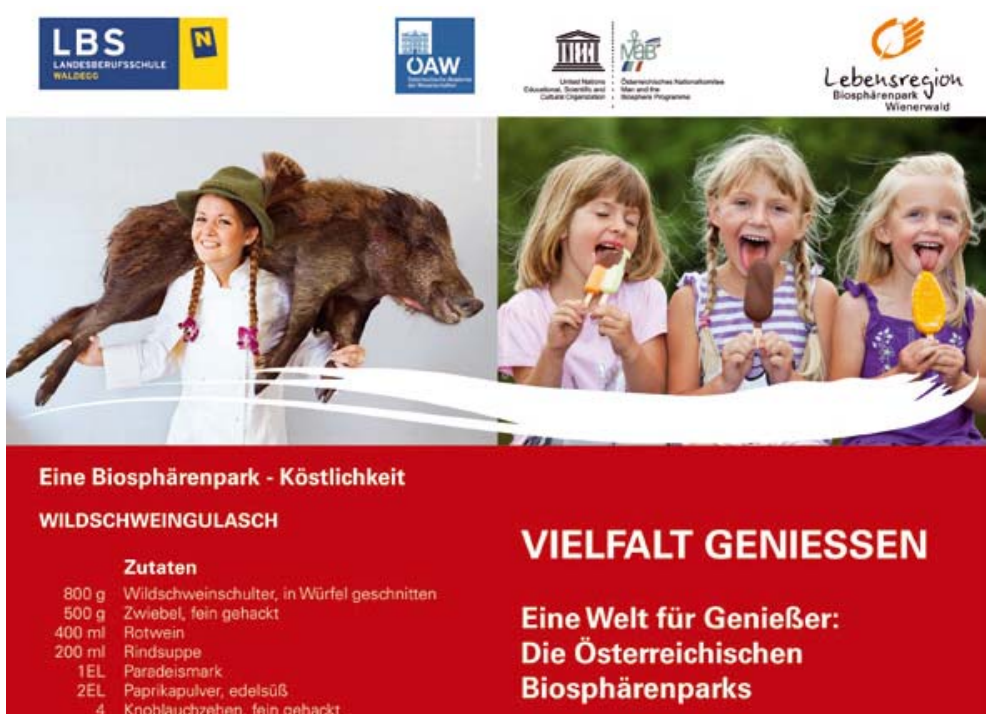

Figure 1 - Detail of the Vielfalt Geniessen Flyer (Enjoying diversity).

and can often lead to contraproductive competition between champions of each conservation category. It is not surprising therefore that such a situation leads to confusion, misunderstandings and, in the worst cases, to indifference in the population. Let me quote an example from my own work: when I travelled to the $21^{\text {st }}$ MAB-ICC 2009 on the South-Korean island of Jeju, the announcement on the plane just before landing pointed out that we were approaching the WHS Jeju. At the conference itself, many MAB representatives deplored the fact that the in-flight announcement had omitted the information that Jeju is also a BR. Here, too, the reason was probably the much higher popularity and status of the WHS label. 


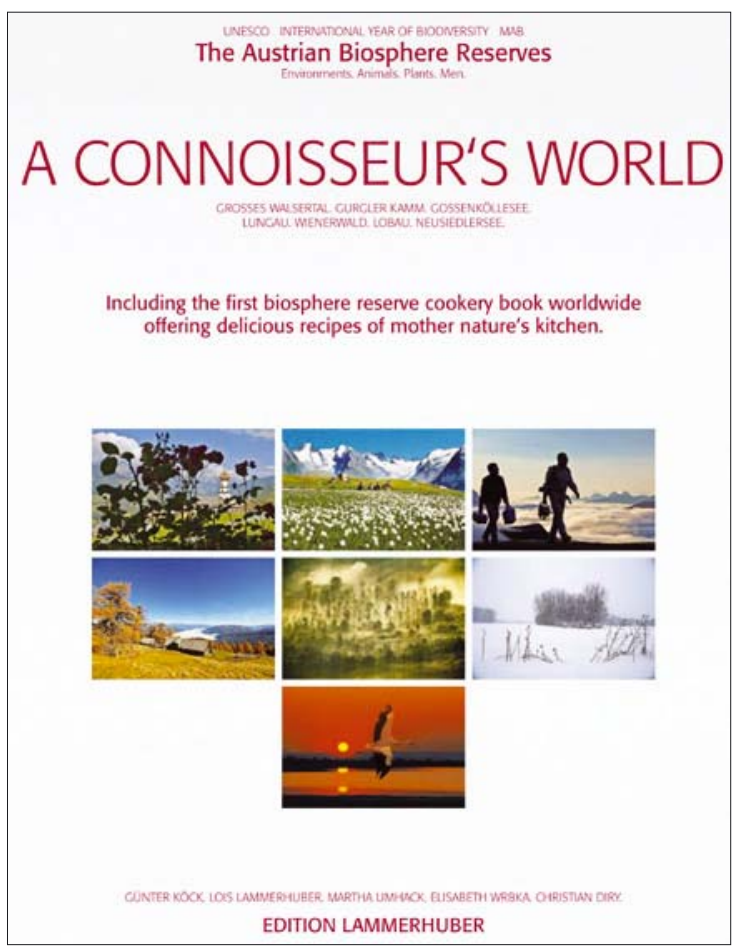

Figure 2 - Book covver of A Connoisseur's World.

It may well be that the tasks and benefits of a national park are easier to communicate than those of a BR. There is an impressive list of expectations directed at BRs (Lange 2005; Köck et al. 2007): they are meant to maintain biodiversity, protect natural resources and support regional development towards becoming a model region for sustainable economic activity. In addition, BRs serve as internationally linked sites of research and education and should promote public awareness of and responsibility for the impact of human activities on the environment. At the same time they are charged with implementing the abstract principle of sustainability in practice in an exemplary way: using innovative approaches and the principle of involving the population and integrating traditional knowledge about using existing resources in ecological, economic and social development strategies. The participation of the population is vital for the successful implementation of the BR concept. In their study, Stoll-Kleemann und Welp (2008) demonstrated that the social acceptance of a BR grows in time with the degree of involvement of the population. To engage the population, however, plenty of well-presented and easily understandable information is needed. Such a campaign is costly, though, and a great burden for underfunded BR managements.

Information gaps are mainly a problem for extensive BRs with large populations, such as Wienerwald BR, where on an area of $1050 \mathrm{~km}^{2}$ some 750000 people need to be addressed (Köck et al. 2009a). Paradoxically, many inhabitants are unaware of the status of their region, even though they have lived in a BR for years (Wittmann \& Engel 2005; Arnberger et al. 2009). This is particularly true of BRs that have been installed by decree from above instead of, as UNESCO recommends, in a bottom-up process over several years with numerous information events and comprehensive stakeholder negotiations.

With the establishment of the new BR Salzburger Lungau und Kärntner Nockberge, plus the existing Wienerwald BR and Großes Walsertal BR, Austria now has a critical mass of three modern BRs, whose existence and concept and whose status as competence centres for sustainability issues should now be promoted to the public at large. This is what the Austrian MAB National Committee set out do. Following the success of the book project Planet Austria (Köck et al. 2009b), which aimed at inspiring young people to engage with the natural sciences, the MAB National Committee was convinced that any BR promotion should also be directed at young people, not least because only by involving the younger generation can behaviours and conceptual frames be changed in the wider society in the longer term.

\section{Vielfalt Genießen (Enjoying diversity) has} been devised as a three-stage programme

First stage: schools competition Vielfalt zum Genießen (Sampling diversity)

For the International Year of Biodiversity 2010, the MAB National Committee funded a competition in the schools of Wienerwald and Großes Walsertal BRs. Pupils were asked to document the value of biodiversity in their immediate environment through the use of edible wild plants in cooking. First, experienced environmental experts took the young people on excursions and introduced them to the natural wealth of the cultural landscape and the diversity of plants in their neighbourhood and pointed out the role and use of these plants. The actual competition that followed challenged the young people to take the initiative. They were to find out from their parents and grandparents stories, experiences and recipes relating to edible wild plants in their neighbourhood and to combine this with the insights gained on the excursions into a presentation to a jury of experts on the Day for Biodiversity 2010 . The best entries were awarded prizes by Wienerwald BR. All in all, young people from 21 school classes participated, submitting some 150 recipes.

Second stage: Austrian BRs cookery book A Connoisseur's World

Encouraged by this success, the MAB National Committee joined forces with award-winning photographic book publisher Edition Lammerhuber to devise a way of communicating the themes of biodiversity/sustainability in a popular-scientific manner. A cookery book would be used as a Trojan horse to present biodiversity and the Austrian BRs as competence centres for sustainability. The culinary highlights should pave the way for information to flow. The cookery book of the Austrian BRs, A Connoisseur's World, came out 
in 2011 (Köck et al. 2011). It contained typical dishes of a region, using regional produce and some rare or forgotten plants (herbs, vegetables, spices), combined with clear information on habitats, animals, plants and people, in an effort to visualize why biodiversity is a key theme for the future that affects the quality of life for everybody. At the same time the 34 recipes in the book entice people to find out more about BRs. The book also points its readers towards using sustainably produced food and to favour regional producers. In the long run this is the only way to ensure a supply of high-quality produce, to secure jobs, to maintain older production techniques, to safeguard the survival of old regional animal and plant species and with it the diversity of food and taste. Staying with the UNESCO idea of BRs as learning sites for sustainable development, the publishers decided not to use well-known chefs to realize the book but to work instead with catering students. The students at the Landesberufsschule (LBS) Waldegg in Lower Austria tested and reproduced the recipes with the help of their teachers. This direct involvement not only gave many young people a hands-on experience of the BR idea, the unusual photographic concept clearly demonstrated the great enthusiasm of the young people for the project, thus attracting younger readers to the book. With added texts in English (The Austrian Biosphere Reserves. A Connoisseur's World) the book is also fit for international use, making Austrian BRs known abroad while introducing non-German speaking BR visitors in Austria to the concept. A large part of the total edition produced was made available to the Austrian BRs for free to support their promotional efforts.

Third stage: school and restaurant initiative Vielfalt Genießen - Mehr als ein Kochbuch (Enjoying diversity - More than a cookery book)

It was clear from the start that the book publication should not be the end of the project and that a sustained impact was needed. This is the key task of the follow-on initiative Vielfalt Genießen - Mehr als ein Kochbuch (Enjoying diversity - More than a cookery book). The successful cooperation with LBS Waldegg provided an ideal base for disseminating the BR concept to the population. During work on the cookery book the great interest of the students in the BR idea became very obvious, which makes them ideal ambassadors and multiplicators of the concept. The project involves training initiatives at LBS Waldegg for students and teaching staff alike. For more than a year, members of the MAB National Committee, together with managers from Wienerwald BR, have been holding training sessions at LBS Waldegg, introducing the final year students (some 300 people) to the BR concept. They focus on key themes, such as species conservation, sustainability and education, in an interactive format, taking Wienerwald BR as a case in point. The students then get further involved by producing a BR leaflet, BR-related menus and similar activities.
Trained in this way, the students can then pass on what they know to the guests of the restaurants they will work in, thus reaching many more people.

In parallel with the initiative at the college, the restaurants in Wienerwald BR were encouraged to put special dishes from Austrian BRs on their menus and label them as such to get their diners interested in BRs. Graduates of the catering college can then supply additional information on BR themes. A special information leaflet on the BR concept, with a BR recipe, was distributed in great numbers and for free to the restaurants for their guests to take away. The initiative aims to make people more aware of the fact that they are living in or visiting a BR and that their active participation and ideas are not just desirable but essential for the successful implementation of the BR concept and for maintaining an environment fit to live in.

\section{Additional initiatives}

The resonance in the press, triggered by the cookery book winning an award at the world's largest cookery book competition (XVII Gourmand Awards 2011), engendered interest even in regions far away from the BR. This allowed the book $A$ Connoisseur's World to be used elsewhere for further BR promotions. One such culinary and musical event took place in the Lower Austrian town of Hollabrunn in cooperation with local culture club Kulturmü $\mu$, LBS Waldegg and Vienna Court theatre actor Robert Reinagl, entitled What can a $B R$ do for your wellbeing? LBS Waldegg regularly provides the catering for numerous popular events which draw large crowds. For more than a year now they have served BR menus almost every time.

\section{Obstacles, benefits, added value}

Normally it is quite difficult to set such initiatives in a school. Many schools have quite tight curricula and the education authorities rarely look kindly at proposed changes. The successful cooperation on the cookery book, however, encouraged the head of school and the education authorities to agree to the follow-up project, which provided added value on top of the regular curriculum for the college and its students.

\section{Infobox}

Recently the whole project Vielfalt Genießen (enjoying diversity) was designated Official Austrian UN Project of the Decade of Education for Sustainable Development 2005-2014 for its continued commitment in the field of education for sustainable development. This distinction is awarded by the Austrian UNESCO Committee, in cooperation with the Federal Ministry for Education, the Arts \& Culture, and the Federal Ministry of Agriculture, Forestry, Environment and Water Management to initiatives that realize the ideas of this global education offensive of the United Nations in an examplary way, communicating sustainable thinking and action to children and adults alike. 
The students training at LBS Waldegg to become catering specialists (chefs, service personnel) thus got to know, in addition to their regular curriculum, how important sustainable use is for maintaining the environment for future generations and learned to recognize their local flora and fauna. In line with the UNESCO definition of BRs as model regions for sustainable development, all three dimensions of sustainability, i.e. economy, ecology and society, were being addressed and best practice examples from the BRs, which combine all three dimensions, presented to the students.

The students, like the readers of the cookery book, are drawn to using sustainably produced food and encouraged to buy from regional producers. By getting closely involved with themes of sustainability, species diversity and species protection in a number of ways (species lists, recipes, designing a leaflet, creating BR menus), the young people internalize the significance of sustainability for the future of us all. By acting in their work placements (usually restaurants) in the $\mathrm{BR}$ region as multiplicators of the BR concept they contribute to maintaining the supply of high-quality produce, jobs, traditional production techniques, old regional species of flora and fauna and with it a diversity of foods and tastes.

In principle it would be good to involve as many restaurants as possible in the initiative. Given the limited funds, the project concentrated on enthusiastic key businesses with a positive attitude to the BR. Many of them send their apprentices to train at LBS Waldegg, which facilitated the connection with the BR-related sessions at the college. The restaurants, who joined the project on a voluntary basis, benefitted from the opportunity of using their location in the BR and their menus of typical dishes of the region, created from locally grown produce to promote their businesses. They were supported in their efforts by the PR undertaken as part of the project.

\section{Feedback from the people involved}

From the start of the schools competition the students did not just receive information in the form of talks but were encouraged to become actively involved in the BR under the guidance of BR experts. Practically all entries to the competition showed ample creativity and enthusiasm for the theme. During the production of the cookery book, the students were closely involved in creating the recipes, testing them and in the photo shoot itself. The training sessions of the third project stage were also designed as interactive events, resulting in concrete project work such as creating an advertising leaflet for the BR or a BR-related menu.

The insights from the project have been regularly debated by the project team and acted upon to improve the project performance. The great success of the schools project, for instance, inspired the team to work with trainee chefs rather than famous established chefs for the cookery book. The young people's sug- gestions for interactive sessions were also integrated to ensure their continued interest in the project. Everything learned in this project will of course be fed into future extensions of the current project and / or transfers to other BRs.

\section{An unqualified success}

The great response in the media (over 70 reports) and the book reviews signify that the concept of the book is a perfect fit with what the market wants and fills a distinct information gap. The excellent results of A Connoisseur's World at the XVII Gourmand Awards 2011 are further proof of the validity of the concept. With a print run of 8000 copies and its distribution through book shops as well, the BR concept has been disseminated to a great many people.

All in all some 900 students were addressed directly in this project. The regular catering activities of LBS Waldegg using BR produce and recipes will bring further students indirectly in contact with the concept and make thousands of visitors aware of the BR idea. In sum, the Vielfalt Genießen initiative reached large parts of the population at comparatively little cost and made them familiar with the BR concept.

The project is also presented on the homepage of the Austrian Academie of Sciences under Science Education (http://www.oeaw.ac.at/english/aktuell/scienceeducation/themen/nachhaltige-entwicklung.html).

In addition the project has been entered into the Austrian education map (Platform for Education for Sustainable Development, ESD). This tool helps to find Austrian organizations that offer learning opportunities for sustainable development. With regard to quality control, a set of criteria for ESD has been developed for www.bildungslandkarte.at that enables potential candidates to evaluate their own ESD performance. Institutions that register and chart one of their projects can also enter it for the award Official Austrian Project of the UN Decade Education for Sustainable Development (2005-2014) assigned by the Austrian UNESCO Commission.

\section{Summary}

The BR concept is ideally suited to maintaining valuable landscapes, cultivated by humans for centuries, for future generation. What is needed for a successful implementation, however, is the involvement and cooperation of the local population. In large areas with high population density it is more difficult to disseminate the relevant information. The Vielfalt $G e-$ nießen (Enjoying diversity) initiative made a significant contribution here by harnessing the enthusiasm of young people in an effort to affect a rethinking in the longer term. It was not confined to addressing young people, though. The catering campaign reached the wider population in all age groups with the BR idea. The cookery book leveraged the continued popular- 
ity of the genre and the increased interest of people in regional produce to get the inhabitants of the BR interested in their environment and in doing their bit for its protection. An ideal way of working towards the UNESCO objective of realizing the abstract principle of sustainability with innovative approaches and by involving as many regional partners as possible. Especially in Austria, which has been experiencing a boom in BR projects in recent years, an information campaign that reaches the wider population beyond the immediate BR area may pave the way for the establishment of more BRs which would otherwise suffer from underinformed potential stakeholders.

\section{References}

Arnberger, A., F. Frey-Roos, R. Eder, G. Muralt, U. Nopp-Mayr, H. Tomek \& M. Zohmann 2009. Ökologische und soziale Tragfähigkeiten als Managementherausforderungen für suburbane Biosphärenparke am Beispiel Untere Lobau. Projektbericht im Rahmen des Man \& Biosphere-Programms der Akademie der Wissenschaften. doi: 10.1553/MAB-OEST. Available at: http://epub. oeaw.ac.at/6781-5inhalt

Coetzer, K.L., E.T.F. Witkowski \& B.F.N. Erasmus 2013. Reviewing Biosphere Reserves globally: effective conservation action or bureaucratic label? Biological Reviews. doi: $10.1111 /$ brv.12044.

Köck, G. \& S. Lange 2007. UNESCO biosphere parks in Austria - model regions for sustainable development. Perspektiven 7: 14-18.

Köck, G., G. Koch \& C. Diry 2009a. The UNESCO Biosphere Reserve „Biosphärenpark Wienerwald“ (Vienna Woods) - a Long History of Conservation. eco.mont 1 (1): 51-56.

Köck, G., L. Lammerhuber \& W.E. Piller 2009b. Planet Austria: Stein - Wasser - Leben. Baden, Wien.

Köck, G., L. Lammerhuber \& M. Umhack 2011. Vielfalt Genießen - Das Kochbuch der österreichischen Biosphärenparks (A Connoisseur's World - The Austrian Biosphere Reserves).

Lange, S. 2005. Inspired by diversity. Available at: http://epub.oeaw.ac.at/3596-3inhalt

Schrader, N. 2006. German biosphere reserves put to the test! Evaluation of existing biosphere reserves with reference to the UNESCO guidelines, the requirements of the national biosphere reserve criteria and the newly developed assessment procedures. Dissertation Universität Trier.

Stoll-Kleemann, S. \& M. Welp 2008. Participatory and Integrated Management of Biosphere Reserves Lessons from Case Studies and a Global Survey. GALA 17/S1: 161-168.
Wittmann, D. \& S. Engel 2005. Zum Gutachten „Biosphärenreservat Rhön: Bekanntheit und Anziehungskraft im Vergleich zu anderen Biosphärenreservaten in Deutschland“. Zusammenfassung und Kommentierung. In: Ott, E. (ed.), Beiträge Region und Nachbaltigkeit: 84-91.

\section{Authors}

\section{Günter Köck}

studied biology at the University of Innsbruck, Austria. His extensive research focuses on biomonitoring studies of aquatic ecosystems. Since 1997 he has led projects of the Austro-Canadian research cooperation High-Arctic. In the year 2000 he was awarded the Canada Prize of the University of Innsbruck. In 2004 he became coordinator of the national and international research programmes of the Austrian Academy of Sciences. He is Secretary-General of the Austrian MAB National Committee, Vice-Chair of the UNESCO MAB Programme, and the Austrian delegate to the European Alliance of Global Change Research Committees, member of the Scientific Board of Hohe Tauern National Park, as well as one of the Austrian delegates to the International Scientific Committee for Alpine Research. In 2009 he became co-editor of eco.mont. In 2010 the Canadian Government recognized his exceptional contributions to Canadian-Austrian relations by awarding him the Canadian Go for Gold honorary medal. He is author of the award-winning books Planet Austria and The Austrian Biosphere Reserves - A Connoisseur's World.

\section{Martha Umhack}

Born in 1964. She teaches business and English for specific purposes at vocational schools. In 2013 she became principal of the Waldegg Vocational School for Tourism in Lower Austria. In addition, she teaches at the Lower Austrian College of Education and works as a consultant on textbooks for the Austrian Federal Ministry for Education, the Arts and Culture.

\section{Christian Diry}

Born 1962 in Vienna. Studied biology (zoology/botany) at the University of Vienna; Master Programme „Management of Protected Areas“ University of Klagenfurt, 2009-2011; tour guide, environmental education, Natural History Museum Vienna; national park ranger, Donauauen NP; since 2004 BR Wienerwald management, responsible for education and sustainability. Contact: cd@bpww.at 